https://helda.helsinki.fi

\title{
Long-term outcomes after pediatric splenectomy
}

\author{
Luoto, Topi T.
}

2016-06

Luoto , T T , Pakarinen , M P \& Koivusalo , A 2016 , ' Long-term outcomes after pediatric splenectomy ' , Surgery , vol. 159 , no. 6 , pp. 1583-1590 . https://doi.org/10.1016/j.surg.2015.12.014

http://hdl.handle.net/10138/224012

https://doi.org/10.1016/j.surg.2015.12.014

publishedVersion

Downloaded from Helda, University of Helsinki institutional repository.

This is an electronic reprint of the original article.

This reprint may differ from the original in pagination and typographic detail.

Please cite the original version. 


\title{
Long-term outcomes after pediatric splenectomy
}

Topi T. Luoto, MD, Mikko P. Pakarinen, MD, and Antti Koivusalo, MD, Helsinki, Finland

\begin{abstract}
Background. Splenectomy is performed frequently for various and primarily hematologic indications in children and adolescents. We analyzed the long-term outcome after splenectomy (median, 8.7 years) focusing on sepsis, portal vein thrombosis (PVT), and retained accessory spleen.

Methods. In total, 141 consecutive children after open $(\mathrm{n}=89 ; 63 \%)$ or laparoscopic $(\mathrm{n}=52 ; 37 \%)$ splenectomy from 1991 to 2010 were followed up through nationwide registries for septic infections, $P V T$, and causes of death. Sixty-six patients (58\% of survivors) answered a structured questionnaire on infections, abdominal symptoms, and general health, and 64 (laparoscopic $\mathrm{n}=26$, open $\mathrm{n}=38$ ) consented to ultrasonography of the portal venous system.

Results. Median operation age was 8.8 years (range, 1.0-22). Reoperations were required for bleeding after open procedures $(\mathrm{n}=1)$ and retained accessory spleen after laparoscopic procedures $(\mathrm{n}=3)$. Postsplenectomy sepsis occurred after a median of 1.7 years (range, 0.2-5.9) in 11 patients (8\%), of whom 10 had an underlying immunodeficiency. No cases of PVT were observed, although the median portal vein flow was $1,130 \mathrm{~mL} / \mathrm{min}$ (range, 440-2200) and diameter was $9.9 \mathrm{~mm}$ (range, 7-15) at a median follow-up of 9.5 years (range, 2.0-22) after splenectomy. Twenty-seven patients (19\%) died after 8.7 years (0.03-23.00). The most common cause of death was the underlying malignancy $(\mathrm{n}=15)$, with sepsis being an additional cause of death in 5 patients.

Conclusion. Postsplenectomy sepsis was associated almost exclusively with an underlying immunodeficiency with a high mortality rate. No PVT was observed. The overall risk of retained accessory spleen was around 7\%, and was slightly greater after laparoscopic operation. (Surgery 2016;159:1583-90.)
\end{abstract}

From the Section of Pediatric Surgery, Pediatric Liver and Gut Research Group, Children's Hospital, University of Helsinki and Helsinki University Central Hospital, Helsinki, Finland

Splenectomy is required often for various, mainly hematologic, indications in children and adolescents. The most common indications are for hereditary spherocytosis, idiopathic thrombocytopenic purpura, sickle cell anemia, and malignant hematologic diseases. ${ }^{1-4}$ The laparoscopic approach is considered the method of choice, and its safety has been proven comparable with the open procedure. ${ }^{1-3,5,6}$ Still, the overall complication risk is around $10 \%$, and even greater if patients with postsplenectomy sepsis are included.

Portal vein thrombosis (PVT) is a potentially lethal complication after splenectomy with a reported incidence of $6 \%$ in children and $\leq 55 \%$ in

The study was supported by the Finnish Pediatric Research Foundation, the Helsinki University Central Hospital Fund, and the Sigrid Jusélius Foundation.

Accepted for publication December 17, 2015.

Reprint requests: Topi T. Luoto, MD, Section of Pediatric Surgery, Children's Hospital, Stenbäckinkatu 11, PL 281, 00029-HUS, Helsinki, Finland. E-mail: topi.luoto@fimnet.fi.

0039-6060/\$ - see front matter

(c) 2016 Elsevier Inc. All rights reserved.

http://dx.doi.org/10.1016/j.surg.2015.12.014 adults with selected hematologic disorders. ${ }^{4,7,8}$ Some patients with PVT are asymptomatic, but abdominal pain and fever develop typically during the first postoperative week, and abdominal ultrasonography (US) confirms the diagnosis., ${ }^{1,4,7}$ PVT predisposes to complicated portal hypertension. ${ }^{7}$ Splenomegaly, thrombocytosis, and concomitant cholecystectomy have been associated with a greater risk of developing PVT after splenectomy, ${ }^{4,7,10,11}$ but a difference between open and laparoscopic procedures has not been found. ${ }^{2,12}$ Treatment of PVT rarely requires surgery, and most authors recommend treatment with antithrombotic and antiplatelet therapy. ${ }^{4,9}$

Other long-term problems after splenectomy are postsplenectomy sepsis, also known as overwhelming postsplenectomy infection, and recurrence of the hematologic disease owing to a retained accessory spleen. ${ }^{13,14}$ The risk of sepsis is greatest during the first 2 years after splenectomy, but remains increased for $>10$ years and probably for life. Children $<5$ years at the time of splenectomy have a greater risk for sepsis than older children and adults. ${ }^{13,15-17}$ The incidence of overwhelming postsplenectomy infection varies 
between 2 and $12 \%$ depending on the preventive measures used, including vaccines and antibiotic prophylaxis, as well as the primary disease leading to the splenectomy. ${ }^{13,18,19}$ In autopsy series, the incidence of an accessory spleen ranges from 4 to $16 \%$ in the general population and from 10 to $30 \%$ in splenectomized patients. ${ }^{20}$ The identification rate is similar in open and laparoscopic procedures. $^{3}$ After splenectomy, an accessory spleen is found in $3-12 \%$ of patients. ${ }^{14}$ A retained accessory spleen can be excised laparoscopically when recurrence of the hematologic disease develops. ${ }^{14,21}$

In the present long-term (median, 8.7 years) follow-up study, we analyzed complications after pediatric splenectomy in a single-center cohort in Finland by assessing episodes of sepsis, PVT, retained accessory spleen, and causes of death through our nationwide registries. A subgroup of volunteers underwent portal venous US examination and answered a structured questionnaire.

\section{PATIENTS AND METHODS}

Study population and design. In total, 141 consecutive pediatric patients who had undergone open or laparoscopic splenectomy in our hospital between 1991 and 2010 were reviewed (Fig 1). Hospital patient records were reviewed completely for demographics, indications for splenectomy, medications, selected laboratory tests and results of blood cultures, infections, findings on abdominal imaging, operative procedures and complications, and survival. All patients were followed up through the Finnish National Care Register for Health Care (National Institute for Health and Welfare, Finland, available at: www.thl.fi/en_US/web/en/ statistics/information/register_descriptions/care register_healthcare\#data) to collect data on episodes of PVT and infections. A systematic search was performed by linking personal identity codes and International Classification of Diseases codes (ICD-9 and ICD-10). The register maintains nationwide data on all given diagnoses and treatments in Finnish hospitals. Causes of death were verified from the nationwide Archive of death certificates of Statistics Finland (available at: www.stat. fi/tup/kuolintodistusarkisto/index_en.html).

A structured questionnaire was sent to all survivors $(n=114)$. Eventually 66 patients $(58 \%$ of survivors) replied, 64 of whom (56\% of survivors) enrolled in the further study, including abdominal US and blood tests (Fig 1). A pediatric radiologist performed abdominal US to evaluate portal vein patency, flow, and diameter. Also assessed was the status of the liver, biliary tract, and kidneys, and presence of an accessory spleen.

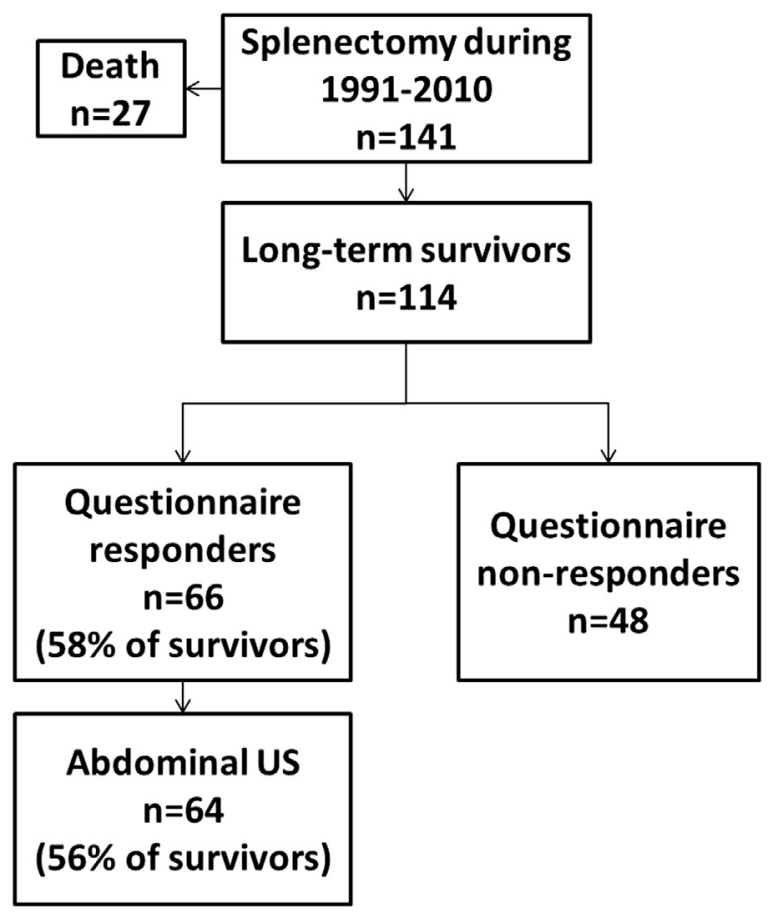

Fig 1. Study population and design. US, Ultrasonography.

Blood tests included hemoglobin, platelet, and leukocyte levels.

Patient management. Preoperative assessment in hematologic patients was done by pediatricians, including clinical examination and blood tests. Patients underwent abdominal US before operation. During the study period, the open approach was replaced by the laparoscopic procedure. In the open method, a left subcostal or transverse incision was cut with the patient in the supine position. Splenic ligaments, short gastric vessels and the main vascular pedicle of the spleen were clamped and ligated. In the laparoscopic method, the patient was positioned in the so-called hanging spleen position with a modified right lateral decubitus position. Insufflation of the peritoneal cavity to $10-15 \mathrm{~mm} \mathrm{Hg}$ was used. After placing 4 trocars, the spleen was mobilized by dividing the named ligaments, short gastric vessels, and the main vascular pedicle with a LigaSure device (Covidien, Mansfield, MA). The completely mobilized spleen was then maneuvered into an endobag, fingerfractured, and removed through an enlarged trocar incision. Exploration of the abdominal cavity was done to identify and remove any accessory spleen. Simultaneous cholecystectomy using an additional operating port on the right abdomen was carried out in patients with symptomatic cholecystolithiasis. 
Hemoglobin, platelet, and leukocyte levels were recorded preoperatively and postoperatively. During the hospital stay, abdominal US was performed in patients with abnormal postoperative abdominal pain. Routine antithrombotic medication was not used. Vaccines (pneumococcal vaccine, Haemophilus influenzae type b conjugate vaccine, and meningococcal conjugate vaccine) were administered $\geq 2$ weeks before splenectomy to all patients. A protocol for revaccination was not used routinely. During the beginning of the study period, use of prophylactic antibiotics had been inconsistent. For the last 15 years, routine antibiotic prophylaxis, mainly with penicillin, for 2 years after splenectomy has been used. Routine follow-up according to the primary disease was done by pediatricians.

Ethics. The study conforms to the principles of the 1975 Declaration of Helsinki and was approved by the research ethics board of the Hospital District of Helsinki and Uusimaa.

Statistical analyses. Data are presented as median values and ranges. Continuous independent variables were compared with Mann-Whitney $U$ test. Comparisons between categorical variables were performed with the Chi-square test. Cumulative survival without sepsis was assessed with the Kaplan-Meier method. SPSS version 22.0 (IBM SPSS Statistics, Armonk, NY) was used for statistical analyses.

\section{RESULTS}

Patient characteristics. Most operations (87\%) were performed for hematologic causes (Table I). Severe hypersplenism and splenomegaly necessitated splenectomy owing to extrahepatic portal vein obstruction (EHPVO) after failed shunt surgery $(n=2)$, and portosystemic vascular malformation, PVT, and Rendu-Osler-Weber disease $(n=1)$. None of the patients in this study underwent splenectomy owing to splenic trauma. Fourteen patients $(10 \%)$ had an associated syndrome, including Hunter syndrome $(n=3)$, cartilagehair hypoplasia $(n=3)$, Down syndrome $(n=2)$, Wiskott-Aldrich syndrome $(n=2)$, and fragile $\mathrm{X}$ syndrome, Goldenhar syndrome, Evans syndrome, and Hurler syndrome ( $n=1$ each). Excluding the condition requiring splenectomy, 89 patients $(63 \%)$ were otherwise healthy. Nine patients $(9 \%)$ had undergone previous abdominal surgery. Overall, 62 patients (44\%) had an immunodeficiency related to the underlying disease or its medical treatment. Of them, 26 patients had a nonmalignant primary disease, including aplastic anemia $(n=10)$, cartilage-hair hypoplasia
Table I. Patient characteristics $(n=141)$

\begin{tabular}{lc}
\hline \multicolumn{1}{c}{ Characteristic } & $\mathrm{n}(\%)$ \\
\hline Male & $75(53)$ \\
Age at splenectomy, $\mathrm{y}^{*}$ & $8.8(1.0-22)$ \\
Preoperative platelets, E9/L* & $199(5-515)$ \\
Spleen length, cm* & $11.3(6.0-23)$ \\
Laparotomy & $83(59)$ \\
Operating time, min* & $67(27-125)$ \\
Laparoscopy & $52(37)$ \\
Operating time, min* & $100(36-181)$ \\
Conversion to open operation & $6(4)$ \\
Simultaneous cholecystectomy & $6(4)$ \\
Reoperations & $4(3)$ \\
Bleeding (open surgery) & $1(0.7)$ \\
Retained accessory spleen & $3(2)$ \\
Indications & \\
Hereditary spherocytosis & $49(35)$ \\
Idiopathic thrombocytopenic purpura & $17(12)$ \\
Malignant disease & $35(25)$ \\
Leukemia & $22(16)$ \\
Lymphoma & $8(6)$ \\
Other nonmalignant disease & $40(28)$ \\
Aplastic/hypoplastic anemia & $13(9)$ \\
Sickle cell disease & $2(1)$ \\
Deaths & $27(19)$ \\
Malignant disease & $15(10)$ \\
Leukemia & $10(7)$ \\
Other nonmalignant disease & $12(9)$ \\
Aplastic anemia & $2(1)$ \\
\hline
\end{tabular}

*Median (range).

$(n=3)$, sickle cell disease $(n=2)$, Wiskott-Aldrich syndrome $(n=2)$, and each with hypogammaglobulinemia, lymphohistiocytosis, interferon-gamma receptor deficiency, lymphangiomatosis, Niemann-Pick disease, histiocytic panniculitis type 2, systemic mastocytosis, chronic granulomatous disease, and common variable immunodeficiency. Thirty-six patients had a malignancy or they have received stem cell transplantation for leukemia $(n=22)$, lymphoma $(n=8)$, osteosarcoma $(n=2)$, and astrocytoma, testicular embryonal carcinoma, neuroblastoma, and Hurler's syndrome $(n=1$ each $)$.

Operative complications and mortality. Conversion to open operation was required owing to hemorrhage $(n=5)$ and adhesions $(n=1)$. Three reoperations were performed for a retained accessory spleen and one for hemorrhage. Twenty-seven patients $(19 \%)$ died during follow-up (median, 8.7 years; range, 0.03-23). Median interval between splenectomy and death was 0.9 years (range, 0.03-7.3), and age at death was 11.2 years (range, 1.9-22.8). The most common cause of death was leukemia $(37 \%)$. None of the patients died owing to PVT or its complications (Table I). 
Table II. Characteristics of patients with postsplenectomy sepsis $(n=11)$

\begin{tabular}{|c|c|c|c|c|c|c|}
\hline $\begin{array}{c}\text { Patient } \\
\text { no. }\end{array}$ & Indication & $\begin{array}{l}\text { Operation } \\
\text { age (y) }\end{array}$ & $\begin{array}{c}\text { Age at } \\
\text { sepsis (y) }\end{array}$ & $\begin{array}{c}\text { Antibiotic } \\
\text { prophylaxis }\end{array}$ & $\begin{array}{c}\text { Blood culture } \\
\text { pathogen }(s)\end{array}$ & Outcome \\
\hline 1 & $\begin{array}{l}\text { Cartilage-hair hypoplasia } \\
\text { with hypoplastic anemia }\end{array}$ & 10.2 & 16.1 & $\begin{array}{l}\text { Various } \\
\text { antibiotics }\end{array}$ & Candida albicans & $\begin{array}{l}\text { Died at } 16 \text { y owing to } \\
\text { intestinal failure } \\
\text { complicated by fungemia }\end{array}$ \\
\hline 2 & Aplastic anemia & 12.8 & 14.4 & Penicillin & $\begin{array}{l}\text { Streptococcus } \\
\text { pneuтопiae }\end{array}$ & $\begin{array}{l}\text { Single pneumococcus sepsis } \\
\text { at } 14 \mathrm{y}\end{array}$ \\
\hline 3 & Leukemia & 10.6 & 11.5 & $\begin{array}{l}\text { Various } \\
\text { antibiotics }\end{array}$ & Candida albicans & $\begin{array}{l}\text { Died at } 11 \text { y owing to } \\
\text { leukemia complicated by } \\
\text { fungemia }\end{array}$ \\
\hline 4 & $\begin{array}{l}\text { Hypersplenism (Rendu- } \\
\text { Osler-Weber disease) }\end{array}$ & 9.6 & 15.1 & No & $\begin{array}{l}\text { Streptococcus } \\
\quad \text { pneumoniae }\end{array}$ & $\begin{array}{l}\text { Single pneumococcus sepsis } \\
\text { at } 15 \mathrm{y}\end{array}$ \\
\hline 5 & Leukemia & 2.8 & 3.3 & $\mathrm{~N} / \mathrm{A}$ & $\begin{array}{l}\text { Streptococcus } \\
\text { pneumoniae }\end{array}$ & $\begin{array}{l}\text { Died at } 3 \text { y owing to } \\
\text { leukemia complicated by } \\
\text { pneumococcus sepsis }\end{array}$ \\
\hline 6 & $\begin{array}{l}\text { Secondary } \\
\text { thrombocytopenia } \\
\text { (osteosarcoma) }\end{array}$ & 11.8 & 15.2 & Penicillin & $\begin{array}{l}\text { Streptococcus } \\
\text { pneumoniae }\end{array}$ & $\begin{array}{l}\text { Died at } 15 \text { y owing to } \\
\text { osteosarcoma complicated } \\
\text { by pneumococcus sepsis }\end{array}$ \\
\hline 7 & Leukemia & 10.6 & 12.8 & Penicillin & $\begin{array}{l}\text { Streptococcus } \\
\text { pneumoniae }\end{array}$ & $\begin{array}{l}\text { Single pneumococcus sepsis } \\
\text { at } 12 \text { y }\end{array}$ \\
\hline 8 & Leukemia & 12.2 & 16.4 & No & $\begin{array}{l}\text { Streptococcus } \\
\quad \text { pneumoniae }\end{array}$ & $\begin{array}{l}\text { Single pneumococcus sepsis } \\
\text { at } 16 \mathrm{y}\end{array}$ \\
\hline 9 & Leukemia & 4.6 & 5.6 & No & $\begin{array}{l}\text { Streptococcus } \\
\text { viridans }\end{array}$ & $\begin{array}{l}\text { Single Streptococcus viridans } \\
\text { sepsis at } 5 \text { y }\end{array}$ \\
\hline 10 & Wiskott-Aldrich syndrome & 6.1 & $6.3^{*}$ & Penicillin & $\begin{array}{l}\text { Streptococcus } \\
\text { pneumoniae }\end{array}$ & $\begin{array}{l}\text { Died at } 10 \text { y owing to } \\
\text { Wiskott-Aldrich syndrome } \\
\text { complicated by } \\
\text { pneumococcus sepsis, } \\
\text { suffered } 4 \text { pneumococcus } \\
\text { sepsis episodes }\end{array}$ \\
\hline 11 & Hurler syndrome & 3.2 & 3.6 & Penicillin & $\begin{array}{l}\text { Staphylococcus } \\
\text { aureus }\end{array}$ & $\begin{array}{l}\text { Single Staphylococcus aureus } \\
\text { sepsis at } 3 \text { y }\end{array}$ \\
\hline
\end{tabular}

*Age at first sepsis.

Postsplenectomy sepsis. Eleven patients (8\%) were admitted for postsplenectomy sepsis during the 8.7 years (range, 0.03-23) of follow-up (Table II). The median interval between splenectomy and the first septic infection was 1.7 years (range, 0.2-5.9). The median age at the time of the first episode of sepsis was 12.8 years (range, 3.3-16.4). Ten patients (91\% of patients with postsplenectomy sepsis) had some element of immunodeficiency related to the underlying disease. The risk for postsplenectomy sepsis was greater among the patients with immunodeficiency (normal immune response in 1 of 79; immunodeficiency in 10 of $62 ; P=.001)$. Cumulative survival without sepsis at $0.5,1,2,5$, and 10 years was $99 \%, 97 \%$, $95 \%, 93 \%$, and $91 \%$, respectively (Fig 2). In 5 patients (leukemia $n=2$, osteosarcoma, Wiskott-Aldrich syndrome, and intestinal failure $n=1$ each), sepsis was classified as an additional cause of death.

PVT. The report of a preoperative abdominal US was available in 104 patients $(74 \%)$ and showed patent portal venous flow in all, excluding 2 patients with EHPVO and 1 with Rendu-OslerWeber disease and PVT. Follow-up abdominal US was performed in 64 patients at a median of 9.5 years (range, 2.0-22) after splenectomy. Twenty-six patients $(41 \%)$ had undergone laparoscopic splenectomy. The patient with Rendu-Osler-Weber disease had persistent PVT on the follow-up US. The EHPVO patients did not participate the follow-up. The remaining 63 patients had a patent portal venous system with median portal vein flow of $1,100 \mathrm{~mL} / \mathrm{min}$ (range, 440-2,200) and a diameter of $9.9 \mathrm{~mm}$ (range, 7.0-15). According to the Finnish Care Register for Health Care, none of the patients $(n=141)$, excluding the 2 patients with EHPVO and the 1 with Rendu-Osler-Weber disease, required treatment for PVT.

Accessory spleen. Overall, an accessory spleen was found in 36 patients (26\%). Preoperative US identified the accessory spleen in $4 \%$ (4 of 104) of the patients. Exploration of the abdominal cavity during splenectomy detected 37 accessory spleens in 28 patients (20\% of all patients); 10, 7, and 1 

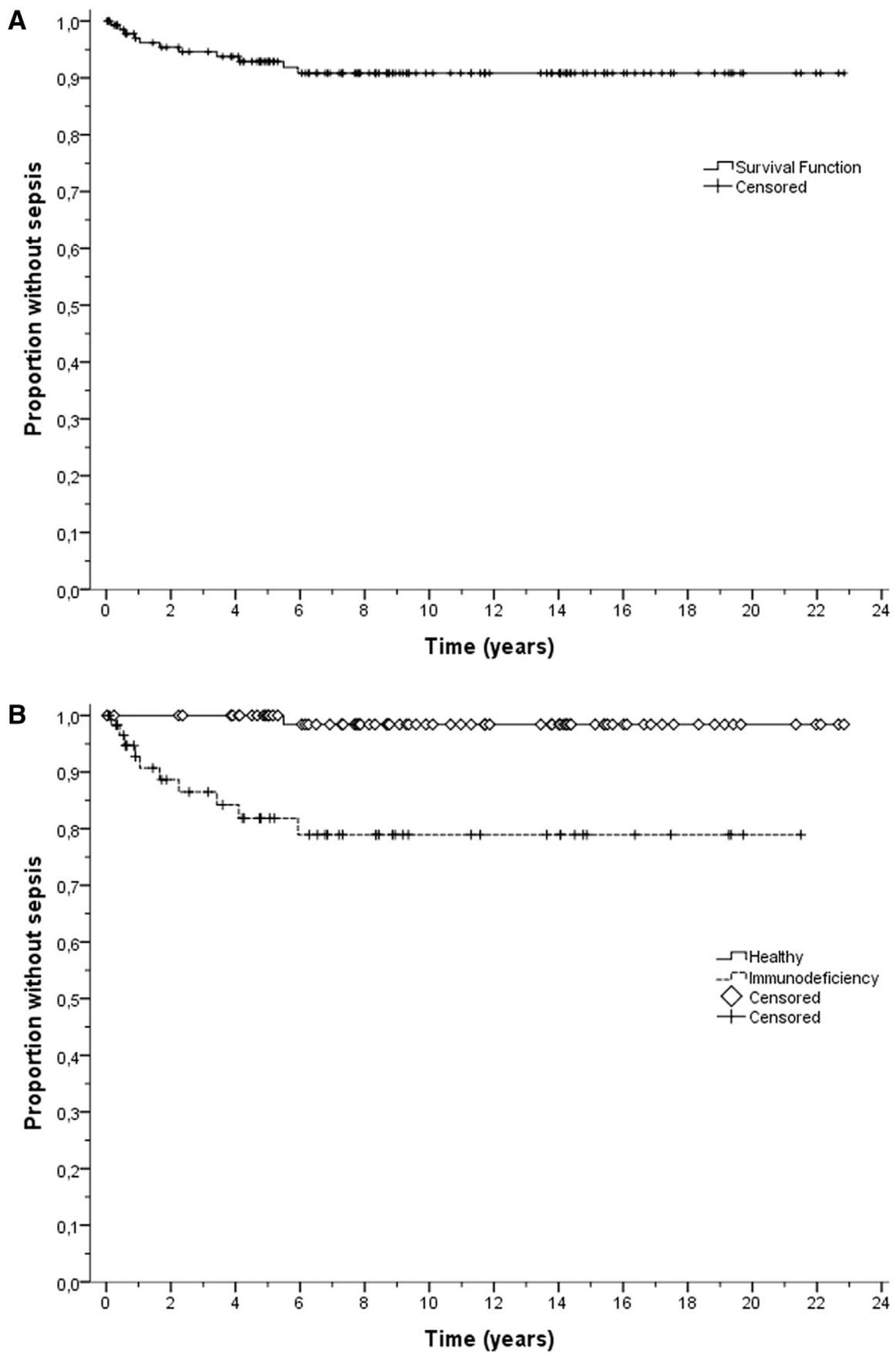

Fig 2. A, Cumulative survival without sepsis for the whole study population ( $\mathrm{n}=141$; Kaplan-Meier curve). $B$, Cumulative survival without sepsis (Kaplan-Meier curve). Upper line presents patients with normal immune response $(n=79)$ and the dash line patients with some element of immunodeficiency $(n=62)$.

patient had 1, 2, and 3 accessory spleens, respectively. Excision was done laparoscopically in 8 patients ( $15 \%$ of patients undergoing laparoscopy) and with an open approach in 20 patients $(23 \%$ of the patients undergoing open surgery). Ten accessory spleens $(28 \%)$ were found near the hilum, 5 in the omentum, and the rest were scattered around the perisplenic area. During follow-up, 3 patients developed recurrence of their hematologic disease after laparoscopic splenectomy and underwent laparoscopic $(n=2)$ or open $(n=1)$ resection of the accessory spleen. In 2 patients of these 3, symptoms resolved. Further on in the follow-up, US ( $n=64$, laparoscopic $n=26)$ identified an accessory spleen in 7 patients (11\%), all of which were asymptomatic. The approach to 
resection was laparoscopic in 4 patients (15\% of patients who had undergone laparoscopic splenectomy) and open in 3 (8\% of the patients who had undergone open splenectomy). No difference was found between operative approaches and accessory spleen detection rate intraoperatively $(P=.38)$ or on follow-up US $(P=.43)$.

Blood count. After a median follow-up of 8.1 years (range, 0.05-22), the hemoglobin, platelet, and leukocyte levels $(n=86$ in all) were $140 \mathrm{~g} / \mathrm{L}$ (range, 74-175), $345 \mathrm{E} 9 / \mathrm{L}$ (range, 9-763), and 7.5 E9/L (range, 0.3-28), respectively. Comparison of hemoglobin, platelet, and leukocyte levels in patients with hereditary spherocytosis and patients without spherocytosis is presented in Table III.

General health and abdominal symptoms. Sixtysix patients answered the questionnaire at a median of 8.7 years (range, 1.4-20) after splenectomy. The responders $(n=66)$ and nonresponders $(n=75)$ were comparable regarding indications, age at operation, sex, operative approach, preoperative platelet level, and spleen size (Table IV). Nine patients ( $14 \%$ of responders) reported a need for hospital admission owing to abdominal pain. In 7 patients, the cause remained unknown, 1 developed a pancreatic pseudocyst, and 1 suffered from intermittent pseudoobstruction. On a numeric scale, ${ }^{1-10}$ the median score of general health quality was 9 (range, 3-10). The most common cause of decreased general health reported by $9 \%$ of patients (6 of 66 ) was recurrent mild upper respiratory tract infections.

\section{DISCUSSION}

The long-term outcome of 141 pediatric patients who underwent splenectomy for hematologic or benign splenic disorders was analyzed based on national registries, hospital patient records, a follow-up questionnaire, and follow-up abdominal US and blood tests. Twenty-seven patients died during the median follow-up time of 8.7 years. The most common cause of death was an underlying malignancy $(n=15)$; in 5 patients, the additional cause of death was sepsis. Overall, 11 patients developed postsplenectomy sepsis, which was associated almost exclusively with an underlying immunodeficiency and developed during the first postoperative years. No patient showed evidence of PVT postoperatively or signs of PVT in the autopsy. The sensitivity of preoperative US in detection of an aberrant spleen was low. An aberrant spleen was detected intraoperatively in $20 \%$ of patients, slightly more often during open surgery. Three patients underwent accessory splenectomy owing to recurrence of the hematologic disease, with resolution of the symptoms in 2 .
Risk of postsplenectomy sepsis depends greatly on the child's primary disease and age. $13,15,16,19,22$ Ten of our 11 patients had an immunodeficiency state related to the primary disease, 6 of whom had a malignancy. One patient had developed complicated portal hypertension secondary to Rendu-Osler-Weber disease before splenectomy and, therefore, had a greater risk for sepsis. During our follow-up, which extended throughout childhood (median age, 19 years; range, 2-43), septic episodes occurred during first 6 years after the splenectomy and before 16 years of age, suggesting that immunocompromised patients could benefit from continuation of postoperative antibiotic prophylaxis beyond 2 years. These results are in line with previous literature, as are our $8 \%$ incidence and $45 \%$ mortality rates for sepsis. ${ }^{13,16,19}$ All 5 patients who died owing to sepsis had a severe primary disease, predisposing them to a lethal septic infection, 3 of whom had a malignant disease. One patient had cartilage-hair hypoplasia with hypoplastic anemia and panintestinal Hirschsprung disease, leading to intestinal failure. The remaining child with a nonmalignant disease had Wiskott-Aldrich syndrome. He suffered 4 septic pneumococcal infections, the last episode of which at age 10 years was fatal.

PVT is a rare complication often related to abdominal surgery and depends on the study population. In retrospective studies, the incidence of PVT after pediatric splenectomy varies between 0 and $10 \% .{ }^{9}$ In a large retrospective heterogeneous series by Rescorla et al, ${ }^{1}$ only 1 episode $(0.4 \%)$ of PVT was reported in 231 children undergone splenic procedures. Routine abdominal US is used only rarely postoperatively in pediatric patients, and only a few studies with US surveillance are available. In the study by Oomen et al, ${ }^{7}$ US was performed within 6 weeks after discharge during the last 2 years of the study period or when there was clinical suspicion of PVT. Of 76 patients with benign hematologic disease, 46 underwent abdominal US, the interval between splenectomy and postoperative US was 5 days to 13.6 years, and 2 cases with PVT were identified. Both patients had undergone simultaneous cholecystectomy. Soyer et $\mathrm{al}^{4}$ performed routine US on the second postoperative day in 68 patients undergoing splenectomy for a hematologic disorder and found PVT in 4. Suggested risk factors for thrombosis were female sex, decreased levels of inhibitors of coagulation, thrombocytosis, and splenomegaly. To the best of our knowledge, our study is the first in which abdominal US has been used systematically to evaluate long-term portal vein patency after 
Table III. Blood count comparison of patients with hereditary spherocytosis and the patients without spherocytosis $(n=83)$

\begin{tabular}{lccc}
\hline \multicolumn{1}{c}{ Variable* $^{*}$} & Spherocytosis $(\mathrm{n}=30)$ & Without spherocytosis $(\mathrm{n}=53)$ & $\mathrm{P}$ value \\
\hline Preoperative & & & .360 \\
Hemoglobin (g/L) & $112(84-143)$ & $114(78-158)$ & .038 \\
Leukocytes (E9/L) & $6.7(4.6-15.7)$ & $5.1(0.1-110)$ & .001 \\
Platelets (E9/L) & $279(195-515)$ & $99(5-420)$ & .001 \\
Follow-up & & $135(74-159)$ & .525 \\
Hemoglobin (g/L) & $147(124-175)$ & $7.4(0.3-27.5)$ & .009 \\
Leukocytes (E9/L) & $7.9(5.0-13.1)$ & $322(9-734)$ & \\
Platelets (E9/L) & $418(217-763)$ & & \\
\hline
\end{tabular}

*Median (range).

Table IV. Comparison of questionnaire responders and non-responders $(n=141)$

\begin{tabular}{lccc}
\hline & Non-responders $(\mathrm{n}=75)$ & Responders $(\mathrm{n}=66)$ & $\mathrm{P}$ value \\
\hline Male $(\%)$ & $41(55)$ & $34(52)$ & .738 \\
Age at splenectomy $(\mathrm{y}) *$ & $9.1(1.4-18)$ & $8.0(1.0-22)$ & .498 \\
Laparoscopic approach $(\%)$ & $27(36)$ & $25(38)$ & .862 \\
Indications (\%) & $21(28)$ & $28(42)$ & .079 \\
$\quad$ Heriditary spherocytosis & $8(11)$ & $9(14)$ & .614 \\
$\quad$ Idiopathic thrombocytopenic purpura & $24(32)$ & $11(17)$ & .050 \\
$\quad$ Malignant disease & $22(29)$ & $18(27)$ & .853 \\
Other non-malignant disease & $101(11-457)$ & $213(5-515)$ & .116 \\
Preoperative platelets (E9/1)* & $11(6-23)$ & $11(6-20)$ & .882 \\
Spleen length $(\mathrm{cm}) *$ & $2(3)$ & $4(6)$ & .419 \\
Simultaneous cholecystectomy $(\%)$ & & & \\
\hline
\end{tabular}

*Median (range).

pediatric splenectomy. Although the study population is heterogeneous and includes various hematologic conditions and patients with high platelet levels and splenomegaly, no cases with PVT were found. More than one-half of the patients underwent US, but when taking in account the comprehensive data from the national registers and comparability of the subgroups (US and non-US), the result may be generalized to the entire study population. A possible explanation to our negative finding may be spontaneous resolution of thrombus during the long follow-up in asymptomatic patients, who did not undergo abdominal US.

A missed accessory spleen can lead to a failed hematologic response, especially in patients with idiopathic thrombocytopenic purpura. ${ }^{23}$ The literature is filled with controversy regarding the accuracy of preoperative computed tomography, US, and scintigraphy, and the intraoperative detection of an accessory spleen. ${ }^{3,14,21,23}$ Our study confirms the low sensitivity of abdominal US. ${ }^{3}$ In our study, 104 patients underwent US preoperatively, which showed an accessory spleen in only 4 patients, but 22 of these patients actually had an accessory spleen found during the operation. Thus, the majority of accessory spleens were identified intraoperatively, and only 3 patients experienced recurrence of the hematologic disease. Removal of the aberrant spleens was accomplished in all of these patients, but follow-up US still showed an accessory spleen in 7 patients. Thus, $\geq 10$ accessory spleens (28\% of all patients with an aberrant spleen) were missed during the operation, and $70 \%$ of patients remained asymptomatic in the long term. Seventy percent of the missed accessory spleens were from the laparoscopic group, and the detection rate intraoperatively was also somewhat less in this group (laparoscopic 15\%, open 23\%). Previous literature reports equivalent detection rates between open and laparoscopic surgery, but without systemic follow-up imaging and the assumption that all patients with a missed accessory spleen were asymptomatic. ${ }^{2,3,24}$ Thus, the actual number of retained accessory spleens is probably much greater.

Our cohort is relatively large and heterogeneous, including all consecutive children after open or laparoscopic splenectomy for various reasons other than for trauma. None of the patients were excluded and, therefore, the results can be generalized. Only $56 \%$ of the survivors underwent abdominal US and blood tests preoperatively and postoperatively, which is a clear 
limitation of the study; however, national registers provided us comprehensive data regarding septic infections and complete data regarding PVT. The register data identified only those patients who required hospital care for PVT not recognizing possible asymptomatic patients. Another shortcoming is the inconsistent antibiotic prophylaxis during the study period. For the last 15 years, mainly penicillin has been used 2 years postoperatively. At the beginning of the study period, antibiotic administration was much more heterogeneous, and some patients received no antimicrobial medication. The patients with a severe underlying primary disease associated with immunodeficiency were given various antibiotics under no consistent protocol. These factors must be taken into account when evaluating the incidence of postsplenectomy infections.

In conclusion, after childhood splenectomy, the risk of developing PVT is very low and essentially nonexistent making US surveillance unnecessary. Postsplenectomy sepsis was almost exclusively associated with an underlying immunodeficiency and had a high mortality rate. The overall risk of a retained accessory spleen was around $7 \%$, being slightly greater after laparoscopic surgery. The majority of accessory spleens are asymptomatic, and abdominal US is an inaccurate method for detection of an accessory spleen. Encouragingly, the recurrence rate of hematologic disorders after splenectomy is low.

\section{REFERENCES}

1. Rescorla FJ, West KW, Engum SA, Grosfeld JL. Laparoscopic splenic procedures in children: experience in 231 children. Ann Surg 2007;246:683-7.

2. Rescorla FJ, Breitfeld PP, West KW, Williams D, Engum SA, Grosfeld JL. A case controlled comparison of open and laparoscopic splenectomy in children. Surgery 1998;124:670-5.

3. Murawski M, Patkowski D, Korlacki W, Czauderna P, Sroka M, Makarewicz W, et al. Laparoscopic splenectomy in children-a multicenter experience. J Pediatr Surg 2008; 43:951-4.

4. Soyer T, Ciftci AO, Tanyel FC, Senocak ME, Buyukpamukcu N. Portal vein thrombosis after splenectomy in pediatric hematologic disease: risk factors, clinical features, and outcome. J Pediatr Surg 2006;41:1899-902.

5. Park AE, Birgisson G, Mastrangelo MJ, Marcaccio MJ, Witzke DB. Laparoscopic splenectomy: outcomes and lessons learned from over 200 cases. Surgery 2000;128:660-7.

6. Winslow ER, Brunt LM. Perioperative outcomes of laparoscopic versus open splenectomy: a meta-analysis with an emphasis on complications. Surgery 2003;134:647-53.

7. Oomen MW, Bakx R, van Minden M, van Rijn RR, Peters M, Heij HA. Implementation of laparoscopic splenectomy in children and the incidence of portal vein thrombosis diagnosed by ultrasonography. J Pediatr Surg 2013;48:2276-80.
8. Ikeda M, Sekimoto M, Takiguchi S, Kubota M, Ikenaga M, Yamamoto $\mathrm{H}$, et al. High incidence of thrombosis of the portal venous system after laparoscopic splenectomy: a prospective study with contrast-enhanced CT scan. Ann Surg 2005;241:208-16.

9. Gelas T, Scalabre A, Hameury F, Dubois R, Grosos C, Mouriquand PD, et al. Portal vein thrombosis after laparoscopic splenectomy during childhood. J Thromb Thrombolysis 2014;38:218-22.

10. Stamou KM, Toutouzas KG, Kekis PB, Nakos S, Gafou A, Manouras A, et al. Prospective study of the incidence and risk factors of postsplenectomy thrombosis of the portal, mesenteric, and splenic veins. Arch Surg 2006;141:663-9.

11. Romano F, Caprotti R, Scaini A, Conti M, Scotti M, Colombo G, et al. Elective laparoscopic splenectomy and thrombosis of the spleno-portal axis: a prospective study with ecocolordoppler ultrasound. Surg Laparosc Endosc Percutan Tech 2006;16:4-7.

12. Vecchio R, Cacciola E, Cacciola RR, Marchese S, Intagliata E. Portal vein thrombosis after laparoscopic and open splenectomy. J Laparoendosc Adv Surg Tech A 2011;21:71-5.

13. Rubin LG, Schaffner W. Clinical practice. Care of the asplenic patient. N Engl J Med 2014;371:349-56.

14. Altaf AM, Sawatzky M, Ellsmere J, Bonjer HJ, Burrell S, Abraham R, et al. Laparoscopic accessory splenectomy: the value of perioperative localization studies. Surg Endosc 2009;23:2675-9.

15. Davies JM, Lewis MP, Wimperis J, Rafi I, Ladhani S, BoltonMaggs PH, et al. Review of guidelines for the prevention and treatment of infection in patients with an absent or dysfunctional spleen: prepared on behalf of the British Committee for Standards in Haematology by a Working Party of the Haemato-oncology Task Force. Br J Haematol 2011;155:308-17.

16. Edgren G, Almqvist R, Hartman M, Utter GH. Splenectomy and the risk of sepsis: a population-based cohort study. Ann Surg 2013;260:1081-7.

17. Boyle S, White RH, Brunson A, Wun T. Splenectomy and the incidence of venous thromboembolism and sepsis in patients with immune thrombocytopenia. Blood 2013;121: 4782-90.

18. Jugenburg M, Haddock G, Freedman MH, Ford-Jones L, Ein SH. The morbidity and mortality of pediatric splenectomy: does prophylaxis make a difference? J Pediatr Surg 1999;34:1064-7.

19. Rodeghiero F, Ruggeri M. Short- and long-term risks of splenectomy for benign haematological disorders: should we revisit the indications? Br J Haematol 2012;158:16-29.

20. Unver Dogan N, Uysal II, Demirci S, Dogan KH, Kolcu G. Accessory spleens at autopsy. Clin Anat 2011;24:757-62.

21. Quah C, Ayiomamitis GD, Shah A, Ammori BJ. Computed tomography to detect accessory spleens before laparoscopic splenectomy: is it necessary? Surg Endosc 2011;25:261-5.

22. Salvadori MI, Price VE, Canadian Paediatric Society, Infectious Diseases and Immunization Committee. Preventing and treating infections in children with asplenia or hyposplenia. Paediatr Child Health 2014;19:271-8.

23. Koshenkov VP, Pahuja AK, Nemeth ZH, Abkin A, Carter MS. Identification of accessory spleens during laparoscopic splenectomy is superior to preoperative computed tomography for detection of accessory spleens. JSLS 2012; 16:387-91.

24. Minkes RK, Lagzdins M, Langer JC. Laparoscopic versus open splenectomy in children. J Pediatr Surg 2000;35:699701. 